\title{
OXYGEN METABOLITE DETOXIFYING ENZYME LEVELS IN BLEOMYCIN-INDUCED FIBROTIC LUNGS
}

\author{
Joseph C. Fantone and Sem H. Phan \\ Department of Pathology, University of Michigan Medical School, Ann Arbor, MI 48109-0602
}

(Received 10 November 1987; Accepted 17 November 1987)

\begin{abstract}
The activities of three enzymes cytosolic superoxide dismutase (SOD), catalase (CAT), and glutathione peroxidase (GSHP), and malonyldialdehyde (MDA), a by-product of lipid peroxidation, were determined in whole lungs of normal and bleomycin-treated rats. Two days after bleomycin treatment total lung SOD, CAT, and GSHP activities were significantly $(p<.025)$ depressed between 15 and $25 \%$. The activities of all three enzymes increased 4 days after bleomycin treatment with only SOD significantly increased at days 4 and 7 . Total lung CAT activity remained near normal levels while GSHP activity increased only at day $28(160.5 \%, p<.01)$ indicating a specificity of the response of lung SOD and GSHP levels. Total lung MDA levels were increased by $17 \%$ at 2 and 4 days $(p<.05)$ after bleomycin treatment, and returned to normal levels at 7 and 28 days. These data suggest that impairment of the lung's ability to detoxify $\mathrm{O}_{2}$ metabolites may play an important role in the development of bleomycin-induced pulmonary fibrosis.
\end{abstract}

Keywords-Anti-oxidant enzymes, Pulmonary fibrosis

\section{INTRODUCTION}

Interstitial pulmonary fibrosis is a frequent sequela of many forms of lung injury, which are associated with the generation of oxygen-derived free radicals and their metabolites. ${ }^{1-6}$ These observations suggest that the inability of the lung to inactivate reactive free radicals and their metabolites may play a role in the initiation of the fibrotic response. Bleomycin, a mixture of glycopeptides derived from Streptomyces verticillus is a potent chemotherapeutic agent and is known to produce interstitial pulmonary fibrosis in humans ${ }^{4}$ as well as experimental animals. ${ }^{7}$ Using an established model of bleomycin-induced pulmonary fibrosis in adult rats, we examined in lung tissue the activities of three antioxidant enzymes cytosolic superoxide dismutase (SOD), catalase (CAT), and glutathione peroxidase (GSHP) in addition to malonyldialdehyde, a by-product of lipid peroxidation at different times after intratracheal instillation of bleomycin.

Address correspondence and reprint requests to: Joseph C. Fantone, M.D., Department of Pathology/Box 0602, The University of Michigan Medical School, 1301 Catherine Road, Ann Arbor, MI 481090602, USA.

\section{MATERIALS AND METHODS}

Reagents and animals

Hydrogen peroxide ( $30 \%$ solution) was obtained from Mallintrodt Inc. (St. Louis, MO). Bleomycin (Blenoxane ${ }^{R}$ ) was a generous gift of Bristol Laboratories (Syracuse, NY). All other chemicals were obtained from Sigma Chemical Co. (St. Louis, MO) and of analytical reagent grade unless otherwise specified.

Groups of four rats (male Fisher 344 pathogen-free rats (150-200 grams) from Charles River [Portage, $\mathrm{MI}]$ ) received bleomycin ( 1.5 units/animal) by intratracheal injection under ketamine (Ketalar ${ }^{\mathrm{R}}$, Parke-Davis, Detroit, MI) anesthesia as previously described. ${ }^{7}$ Control animals received sterile saline instilled intratracheally.

\section{Enzyme assays}

At specific time intervals after bleomycin administration four bleomycin-treated and four control animals were sacrificed and their lungs perfused with 10 $\mathrm{ml}$ of saline. Each lung was isolated, minced, and homogenized with a polytron (Brinkman Instrument, 
Westbury, NY) in $4 \mathrm{ml}$ of phosphate-buffered saline (PBS), $5 \mathrm{mM}$ EDTA, and $0.1 \%$ Triton X-100. $1.5 \mathrm{ml}$ of homogenized suspension was removed to be assayed for MDA content. The remaining $2.5 \mathrm{ml}$ were centrifuged $\left(105,000 \times \mathrm{g}, 60 \mathrm{~min}, 4^{\circ} \mathrm{C}\right)$, the supernatants removed, filtered through $0.65 \mu \mathrm{m}$ filters and assayed for total lung protein. ${ }^{8}$ Lung CAT activity was assayed by determining the initial rate of decrease in absorbance at $240 \mathrm{~nm}\left(\varepsilon=1.308 \times 10^{-4} \mu \mathrm{M}^{-1} \mathrm{~cm}^{-1}\right.$, for $\mathrm{H}_{2} \mathrm{O}_{2}$ ) after the addition of $20 \mu \mathrm{l}$ lung supernatant into $0.98 \mathrm{ml}$ of $0.2 \mathrm{M} \mathrm{H}_{2} \mathrm{O}_{2}$ in $50 \mathrm{mM}$ potassium phosphate

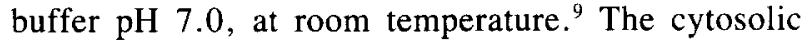
SOD activity in each lung was determined by the method of Misra and Fridovich. ${ }^{10}$ One unit of SOD activity was defined as the amount of lung supernatant which produced 50\% inhibition of the spontaneous auto-oxidation of epinephrine to adrenochrome. The assay was performed in $0.05 \mathrm{M}$ sodium carbonate buffer $\mathrm{pH} 10.2$, containing $10^{-4} \mathrm{M}$ EDTA, at room temperature and monitored at a wavelength of $480 \mathrm{~nm}$. Fifty percent inhibition was observed in the range of 10 to $30 \mu \mathrm{l}$ of lung extract. Glutathione peroxidase activity was determined by the method of Paglia and Valentine. ${ }^{11}$ Twenty $\mu l$ of lung extract was added to a $1.0 \mathrm{ml}$ reaction mixture containing $0.13 \mathrm{M}$ sodium phosphate, $\mathrm{pH} 7.0$ at room temperature, $0.013 \mathrm{M}$ EDTA, $.011 \mathrm{M}$ sodium azide, $.015 \mathrm{M}$ glutathione (reduced form), 0.84 $\mathrm{mM}$ NADPH, $1.0 \mathrm{unit} / \mathrm{ml}$ glutathione reductase, 0.22 $\mathrm{mM} \mathrm{H} \mathrm{H}_{2}$. The initial rate of decrease in absorbance was determined at $340 \mathrm{~nm}\left(\varepsilon=6.22 \times 10^{3} \mathrm{M}^{-1} \mathrm{~cm}^{-1}\right.$ for NADPH).

\section{MDA assay}

The malonyldialdehyde content of lung homogenates was determined by assaying the quantity of thiobarbituric acid (TBA) reactive products present. ${ }^{12} 1.5$ mls of $0.8 \%$ TBA in $10 \%$ trichloroacetic acid were added to $0.5 \mathrm{ml}$ of each lung homogenate, vortexed, and placed in a boiling water bath for 10 minutes. The reaction mixtures were allowed to cool, $1.0 \mathrm{ml}$ of $1 \mathrm{~N}$ $\mathrm{NaOH}$ added, and centrifuged at 2,000 xg for 20 minutes. The absorbance of the supernatant was determined at $532 \mathrm{~nm}$ and the quantity of MDA determined $\left(\varepsilon=1.56 \times 10^{5} \mathrm{M}^{-1} \mathrm{~cm}^{-1}\right)$.

\section{Statistical analysis}

All enzyme assays and MDA determinations were conducted in triplicate for each lung sample. Mean values for reach lung sample and mean values for each group of four bleomycin-treated and four control animals were determined at each time point and the data expressed as percent change compared to controls. A two factor mixed design (repeated measures on one factor) analysis of variance technique was used to determine $p$ values between control and bleomycin-treated groups. ${ }^{13}$

\section{RESULTS}

The relative amounts of MDA present in the lungs of bleomycin-treated animals as compared to control animals is shown in Figure 1. There was a small but significant increase in total thiobarbituric acid reactive material present in the lungs of the treated animals, reaching a maximum of $117 \%$ of control values $(p<$ $.05)$ at day 4 post-bleomycin instillation and returning to normal levels by days 7 and 28 . When normalized to $\mathrm{mg}$ total lung protein, there is a significant increase in the levels of MDA (23.6\% above control animals, $p<.05$ ) two days post-bleomycin treatment. This was followed by a decrease below control values of $15.8 \%$ at 4 days, $16.8 \%$ at 7 days, and $35.5 \%$ at 28 days after bleomycin treatment.

Total lung cytosolic SOD activity was depressed (75.3\% of control values $p<.02$ ) at day 2 after bleomycin treatment (Fig. 2). This was followed by an increase in SOD activity at day 4 , reaching a maximum at day $7(147.9 \%$ of control levels, $p<.02)$ and returning towards control levels at day 28 . When normalized per mg total lung protein, the SOD activity was attenuated similar to MDA, however, the changes were not significantly different from control values. Total lung catalase activity was decreased at 2 days

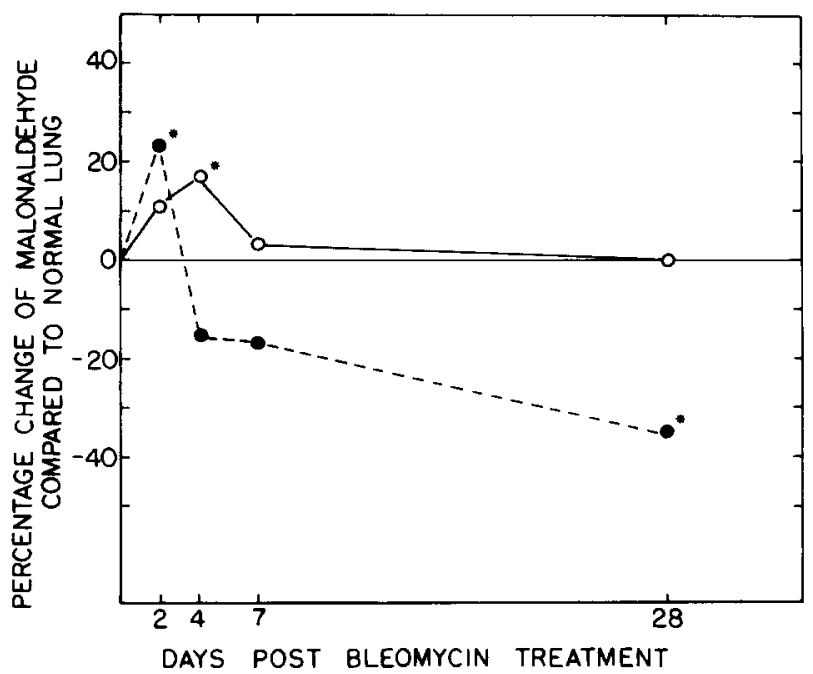

Fig. 1. Effect of bleomycin treatment on lung MDA content. MDA levels in lungs of control and bleomycin-treated animals were determined. The percent change in lung MDA levels in bleomycintreated animals compared to normal lungs was determined. $\mathrm{O}-\mathrm{O}$ $=$ total lung MDA activity; - -1 lung MDA activity $/ \mathrm{mg}$ total lung protein; $*=p<.05$. 


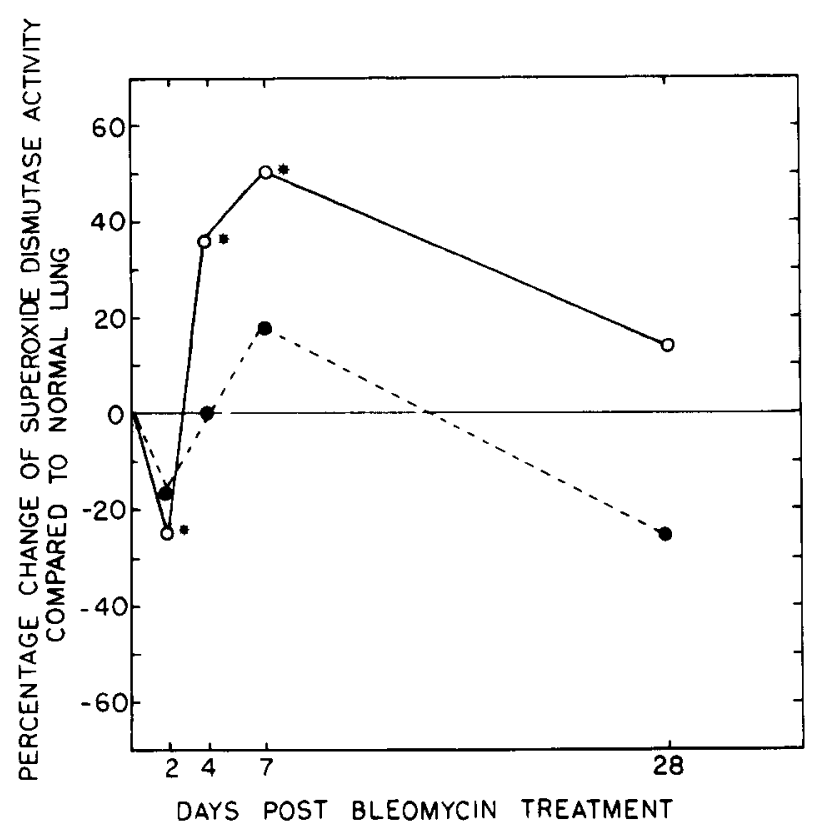

Fig. 2. Effect of bleomycin treatment on lung SOD activity. SOD activity in supernatants of homogenized lung was determined in both bleomycin-treated and control animals. The percent change in lung SOD activity in bleomycin-treated animals compared to controls was determined. $\mathrm{O}-\mathrm{O}=$ total lung SOD activity; $-\longrightarrow=$ lung SOD activity $/ \mathrm{mg}$ total lung protein; ${ }^{*}=p<.05$.

(75.9\% of control values, $p<0.025$ ) after bleomycin treatment, returning to control levels at days 4,7 , and 28 (Fig. 3). When normalized per mg total lung protein, there was a significant decrease in CAT activity after bleomycin treatment. An initial nadir of $27.1 \%$

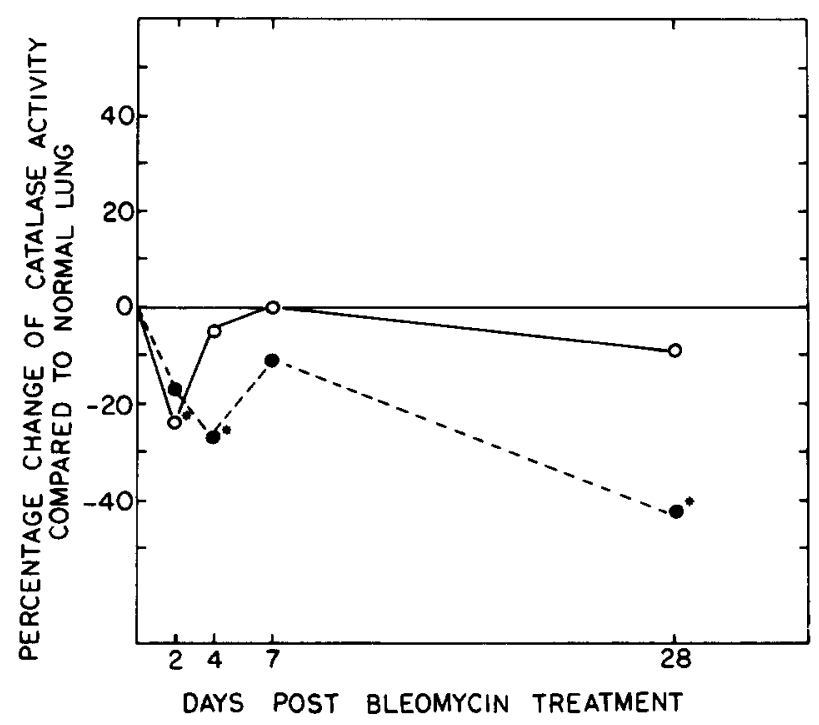

Fig. 3. Effect of bleomycin treatment on lung CAT activity. CAT activity was determined in supernatants of lung homogenates from bleomycin and control animals. The percent change in lung CAT activity in bleomycin-treated animals compared to control animals was determined. $\mathrm{O}-\mathrm{O}=$ total lung CAT activity,

lung CAT activity/mg total lung protein; ${ }^{*}=p<.05$.

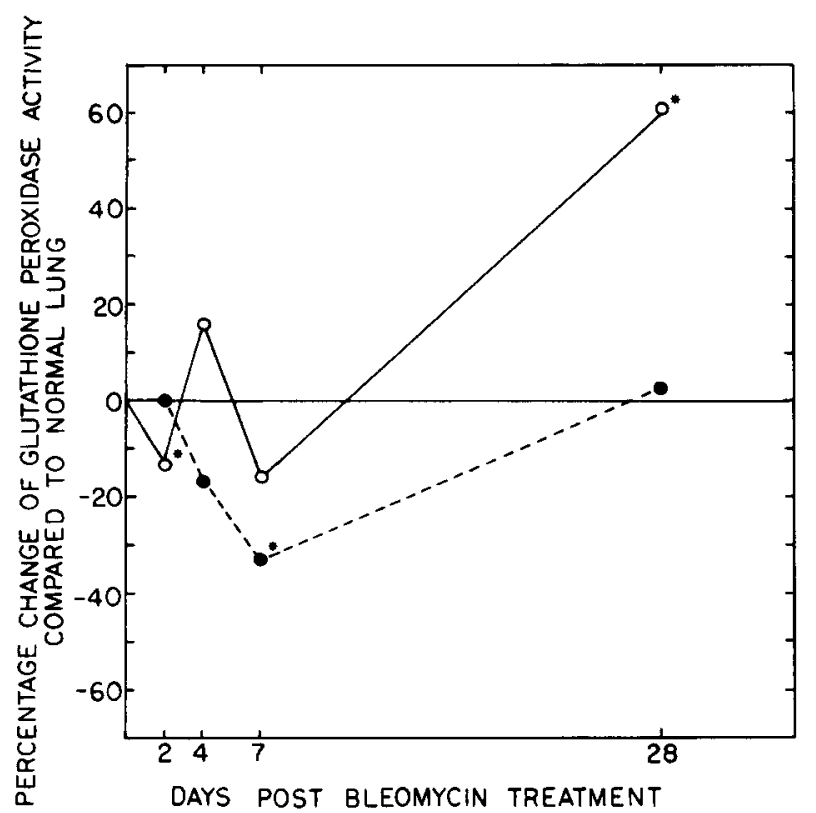

Fig. 4. Effect of bleomycin treatment on lung GSHP activity. GSHP activity was determined in supernatants of lung homogenates from bleomycin and control animals. The percent change in lung GSHP activity in bleomycin-treated animals compared to control animals was determined $\mathrm{O}-\mathrm{O}=$ total lung GSHP activity; $--\mathrm{O}=$ GSHP activity/mg total lung protein; ${ }^{*}=p<.05$.

below control values $(p<.02)$ was observed 4 days after bleomycin treatment. At 7 days the CAT activity per $\mathrm{mg}$ lung protein increased to $89.4 \%$ of control levels and at 4 weeks decreased to $42.5 \%$ below control levels $(p<.01)$.

There was a decrease in total lung GSHP activity when compared to control levels $(86.4 \%, p<.025)$ at day 2 after bleomycin treatment (Fig. 4). However, at days 4 and 7 posttreatment, there was variability in the content of GSHP in whole lung extracts, which were not significantly different than control values. In contrast to catalase, there was a marked increase in total lung GSHP activity ( $160.5 \%$ of control levels, $p$ $<0.1)$ at day 28 . When GSHP activity was determined per mg lung protein there was no difference between bleomycin-treated and control animals at 2 days. However, the GHSP activity decreased at 4 and 7 days (32.7\% below control values, $p<.05$ ) after treatment. At day 28 , the GSHP activity per mg lung protein returned to normal levels.

\section{DISCUSSION}

During the first week post-bleomycin treatment there is a transient increase in total lung MDA. This occurs at the time of greatest acute tissue injury. The apparent decrease in TBA reactive products when normalized per $\mathrm{mg}$ total lung protein at days 4 and 7 was most 
likely due to increases in total lung protein resulting from the inflammatory infiltrate. The significant decrease at day 28 was most likely the result of increases in total lung mass (usually $50 \%$ above controls) and protein, especially collagen which has been reported to be $80 \%$ greater than control values. ${ }^{7}$

Although there is no direct evidence for lipid peroxidation occurring in bleomycin-injured lungs, it is well established that free radicals have the potential to generate lipid peroxides and MDA. ${ }^{12}$ There are several potential sources of free radical production in the lungs of bleomycin-treated animals. Bleomycin has been shown to generate free radicals in vitro and to alter DNA structure through the action of an iron-bleomycin complex. ${ }^{14}$ However, since the quantity of bleomycin used to induce lung injury is relatively small ( 1.5 units/ animal), it is more likely that the increased levels of MDA are secondary to the inflammatory infiltrate. ${ }^{15}$ An alternative explanation for the rise in total lung MDA content is the marked decrease in oxygen metabolite detoxifying enzyme activities occurring after bleomycin treatment. Lipid peroxidation within the lung may result from oxygen metabolite generation within resident lung cells whose ability to metabolize normally occurring reactive products is impaired. After one week post-bleomycin treatment the MDA levels returned to control levels. This corresponds with the return to normal and/or increased levels of $\mathrm{O}_{2}$ detoxifying enzyme activities. The relative decrease in the total lung activities of SOD, CAT, and GSHP after bleomycin treatment, despite the presence of intra-alveolar hemorrhage and inflammation suggests an inactivation (possibly due to oxygen metabolites ${ }^{16}$ ) and/ or decreased synthesis (potentially secondary to bleomycin-induced DNA destruction) of these enzymes. This would potentially predispose the lung to injury by free radicals.

After the initial decrease in total lung SOD and GSHP levels there was a significant increase above control values in both enzyme activities at one and four weeks, respectively. This increase in enzyme activities is similar to that observed with experimental models of hyperoxia-induced lung injury. ${ }^{17.18}$ However, there appears to be a specificity in the response of bleomycintreated animals, since lung catalase levels were not increased above control values. In conclusion, the data demonstrate a time-dependent increase in MDA content and suppression of oxygen metabolite detoxifying enzymes in the lung after bleomycin treatment suggesting a role for oxygen metabolites and free radicals in bleomycin-induced lung injury.

Acknowledgement-Supported in part by NIH grants HL-28737 and HL-32024.

\section{REFERENCES}

1. Gross, N. J. Pulmonary effects of radiation therapy. Ann. Int. Med. 86:81-92; 1977.

2. Chvapil, M.; Peng. Y. M. Oxygen and lung fibrosis. Arch. Environ. Health 30:528-532; 1975.

3. Autor, A. P.; Schmitt, S L. Pulmonary fibrosis and paraquat toxicity. In: Autor, A. P., ed. Biochemical mechanisms of paraquat toxicity. London and New York: Academic Press; 1977:175-186.

4. Weiss, R. B.; Muggia F M. Update cytotoxic drug-induced pulmonary disease. Amer. J. Med. 68:259-266; 1980.

5. Hunninghake, G. W.; Fauci, A. S. Pulmonary involvement in the collagen vascular diseases. Amer. Rev, Respir. Dis. 119. $471-503$

6. Johnson, K. J.; Fantone, J C.; Kaplan, J., Ward, P. A. In vivo damage of rat lungs by oxygen metabolites. $J$ Clin. Invest. 67:983-993; 1981.

7. Phan, S. H.; Thrall, R S.; Ward, P. A. Bleomycin-induced pulmonary fubrosis in rats: Demonstration of increased rate of collagen synthesis. Amer. Rev. Respir. Dis. 121:501-506; 1980.

8. Lowry, O.; Rosebrough, N. J.; Farr, A. C.; Randall, R. J. Protein measurement with the folin phenol reagent. J. Biol. Chem. 193:265-270; 1951.

9. Beers, R. F.; Sizer, I W. A spectrophotometric method for measuring the breakdown of hydrogen peroxide by catalase. $J$ Biol. Chem. 195:133-139, 1952.

10. Misra, H. P.: Fridovich. I. The role of superoxide anion in the auto-oxidation of epinephrine and a simple assay for superoxide dismutase. J. Biol. Chem. 247:3170-3175; 1972

11. Paglia, D. E.; Valentine, W. N. Studies on the quantitative and qualitative characterization of erythrocyte glutathione perox1dase. J. Lab. Clin. Med 70:158-169; 1967

12 Chow, C. L. K.; Tappel, A. C. An enzymatıc protective mechanism against lipid peroxidation. Lipids 7:518-524; 1972.

13. Brunı, J L., Kintz, B. L. In: Computational handbook of statistics Dallas, TX: Scott, Foresman, and Company; 1978:5559.

14 Lin, P S.; Kwock, L, Goodchild, N. T. Copper chelator enhancement of bleomycin cytotoxicity. Cancer 46:2360-2364; 1980.

15 Klebanoff, S. Oxygen metabolism and the toxic properties of phagocytes. Ann. Int. Med. 93:480-489; 1980.

16. Carp, H.; Janoff, A. Potential mediator of inflammation. Phagocyte-derived oxidants suppress the elastase-inhibitory capacity of alpha-proteinase inhibitor in vitro. J. Clin Invest. 66:987995,1980

17. Stevens, J. B.; Autor, A. P. Oxygen induced synthesis of superoxide dismutase and catalase in pulmonary macrophages of neonatal rats. Lab. Invest. 37:470-478, 1977.

18. Forman, H. J.; Fisher, A. B. Antioxidant enzymes in rat granular pneumocytes. Constitutive levels and effect of hyperoxia. Lab. Invest. 45:1-6; 1981 